\title{
GRUPOS DE PESQUISA ONLINE: PRÁTICAS DE ORIENTAÇÃO COLETIVA NO ENSINO SUPERIOR
}

Rosemary Santos*

INTRODUÇÃO

\author{
"Escrever é estar no extremo \\ de si mesmo, e quem está \\ assim se exercendo nessa \\ nudez, a mais nua que há, \\ tem pudor de que outros vejam \\ o que deve haver de esgar, \\ de tiques, de gestos falhos, \\ de pouco espetacular \\ na torta visão de uma alma \\ no pleno estertor de criar. ", \\ João Cabral de Melo Neto
}

Buscar compreender o processo formativo que atravessa a docência é criar um exercício interpretativo de autoria e de produção discursiva e teórica, interpretar, interpretando-se, recriando, inclusive, os modos de pensar e de fazer novas Educações (PRETTO, 2010). Implica ao mesmo tempo, compreender os dilemas docentes, o próprio papel do professor, suas relações com os alunos, com a arte, com o movimento da cidade, com as políticas dos governos e com as tecnologias.

Assim, desejamos efetivar uma crítica aos equívocos com os quais o conceito de formação tem sido usado de forma elevada, prescritiva. Pretendemos distinguir e apresentar uma noção dentro do que Macedo (2010) chama de uma perspectiva epistemológica e pedagógica, complexa, cujo sentido central se constitui como ato de compreender compreendendo de forma significativa e socialmente referenciada.

Baseada na argumentação de Morin (2006) e de Macedo (2010), reiteramos que a formação é fruto de um encontro entre praticantes culturais ${ }^{1}$ e permite que um compreenda o que vive o outro,

\footnotetext{
${ }^{(*}$ Rosemary Santos. Professora Adjunta do Departamento de Formação de Professores da Faculdade de Educação da Baixada Fluminense (FEBF-UERJ). Vice-coordenadora do GPDOC - Grupo de Pesquisa Docência e Cibercultura. Tutora de Educação a distância. Site: www.docenciaonline.pro.br. E-mail: rose.brisaerc@gmail.com
} 
tomando-o em conjunto, enredando, cocriando. O caminho que fizemos em direção à busca dessa compreensão é o que traremos neste texto. Por meio da tessitura das narrativas dos professoresformadores e seus orientandos nos grupos de pesquisa online, procuramos discutir a importância de compreender como esses processos de orientação podem também ser efetivados numa rede social.

A escrita deste textonos nos trouxe o desafio de compreender o processo de orientação como prática docente, de negociação, do trabalho em parceria, de pesquisa como formação, ou seja, a docência se insere em um cenário no qual escrever o texto acadêmico não se resume a realizar uma atividade de caráter científico como parte importante para se concluir o curso somente, mas também, enquanto se realiza o trabalho de pesquisa, faz acontecer a atividade de formação dos praticantes pesquisadores: "aquele que, ao elaborar o trabalho em pauta, é capaz de desenvolver a noção do próprio trabalho e, mais ainda, aperceber-se de si” (BARBOSA, 2014, p.82).

Nesta pesquisa, as conversas com os praticantes e seus orientandos, a imersão nas redes sociais em que estes habitam, a participação nos grupos de pesquisa online e nas conversas na universidade, nos fez desenmvolver a escuta sensível (BARBIER, 2002). O companhamento de seus rastros na rede foram fundamentais para essa compreensão, assim, lançamos mãos de alguns pressupostos epistemológicos e metodológicoa para fundamentar a pesquisa.

\section{A EXPERIÊNCIA FORMADORA DA CIBERPESQUISA-FORMAÇÃO COMO MÉTODO DE PESQUISA}

Ao trazer na metodologia a formação de formadores na cibercultura como objeto desta pesquisa, partimos do pressuposto de que o fundante da Educação é a formação (MACEDO, 2010) e que todo ato de ensinar e toda criação curricular passam necessariamente pela preocupação com essa experiência social, política, acadêmica e afetiva. Assim, tomamos como referência nesta experiência formadora a ciberpesquisa-formação como método de pesquisa no contexto da cibercultura. Pretendemos atualizar o conceito de pesquisa-formação pela própria especificidade do contexto contemporâneo, ao perceber, hoje, um cenário múltiplo, complexificado pela diversidade de dispositivos tecnológicos e possibilidades de apropriações e desvios da configuração midiática, pois, a partir de um movimento dialético entre a técnica, a cultura e a sociabilidade, somos atravessados pelos limites da participação nos espaços online e offline. Para Santos, E: 
ensinar e aprender a partir do compartilhamento de narrativas, sentidos e dilemas de docentes e pesquisadores pela mediação das interfaces digitais concebidas como dispositivos de pesquisa-formação (SANTOS, E, 2005, p.74).

Ao optar pela epistemologia da multirreferencialidade e pelo método da ciberpesquisaformação, vimos reafirmar que esta é uma opção política e faz contraponto aos pressupostos teóricos positivistas, tão sedimentados no campo educacional. Segundo Ardoino (1998), o surgimento da multirreferencialidade está ligado ao reconhecimento da complexidade e da heterogeneidade inerentes às práticas educativas, sempre na perspectiva de uma pluralidade de olhares e linguagens, reconhecidas como necessárias à compreensão do fenômeno complexo que é a Educação.

É necessário que reconheçamos essa heterogeneidade como própria do campo das ciências humanas, visto que elas se caracterizam pela possibilidade de coexistência temporal de várias perspectivas teóricas, várias abordagens e vários paradigmas. O fato de aproximarmos perspectivas teóricas marcadas pela heterogeneidade nos permite mergulhar em um campo de tensão, a partir do qual podemos vislumbrar novas referências e novos campos de pesquisa para a compreensão dos fenômenos humanos. A heterogeneidade é uma das marcas de todo o sistema educacional, apesar de, em muitas oportunidades, se negar essa realidade, ou ainda, se pressupor uma homogeneidade que não existe.

O reconhecimento da necessidade de compreender os múltiplos elementos e fatores para a compreensão dos fenômenos educativos implica obrigatoriamente o rompimento com a linha de pensamento linear, unitário e reducionista, característica dos modelos cartesianos/positivistas, ainda hoje utilizados como "certos", "verdadeiros" e "infalíveis", quando se pretende entender a realidade e construir conhecimento.

A multirreferencialidade exige e comporta uma bricolagem de dispositivos quando o pesquisador elabora uma hipótese a respeito do objeto. Trata-se essencialmente "de ir aqui e lá, eventualmente para obter, pelo desvio, indiretamente, aquilo que não se pode alcançar de forma direta" (Ardoino, 1998, p.203). Tal procedimento não dispensa o rigor, mas adota um rigor outro (MACEDO, 2000), diferente do cartesiano, para se trabalhar com uma abordagem que cria espaço para o entrecruzamento de múltiplas perspectivas, nos inspirando nessas múltiplas perspectivas, acionamos ambiências formativas que articulavam o espaço da universidade e das redes sociais criando redes de docência e aprendizagem interagindo nas redes sociais e participação nos Grupos de Pesquisa Online. 
Essa epistemologia parte da incompletude, das borras, da falta, produzida pelo inacabamento que nos configura, identifica-nos e, ao mesmo tempo, nos constitui como no dilema trazido por uma das professora-formadora da pesquisa em uma de nossas conversas:

A minha pesquisa é sobre a formação do formador na cibercultura, e o objetivo da pesquisa é tentar compreender se é possível a gente pensar formação em outros espaços, que não seja só o espaço da Universidade. É para a gente pensar e tentar mesmo compreender que formação é essa, se é apenas uma formação pedagógica mesmo. Dentro dos grupos de pesquisa na Instituição, dentro de outros espaços tempos de aprendizagem, então como a gente pode compreender essa formação? Será que é possível a gente pensar também essa formação no Facebook, nos grupos de pesquisa online, nos sites das redes sociais, será que a gente pode pensar dessa forma? E uma pergunta inicial, eu não planejei nada, mas já conversei com outros professores de outras linhas de pesquisa, quais são os seus usos das redes sociais, você usa dispositivos móveis? Você usa redes sociais frequentemente também para a pesquisa? Ou para outros usos? (PESQUISADORA)

Então, é isso, tem uma hora que é difícil de você separar se é uma coisa pedagógica ou não, porque eu acho que a questão é definir isso, o que se transforma em pedagógico, é muito relativo. Por exemplo, eu tenho posto agora coisas sobre questão política, com os meus alunos, o que geralmente... o que eu compartilho marcando com eles são as coisas que têm a ver com o estudo que eles fazem. Para isso, digo: "Nxxx, estou te marcando aqui como aluna". Ao mesmo tempo, de vez em quando eu ponho coisas que têm a ver com a relação que a gente criou que vai para fora daquilo. Nem [com] todos os alunos eu construo essa relação, e acho que não é para construir com todos os alunos, nem com os colegas da Universidade. Então eu acho assim, o tema talvez seja definido de acordo com a relação que está sendo construída. Porque quando eu marco, "Olha isso, Rose"; quando eu marco, "Olha isso, Nxxx", a Nxxx está proibida de não olhar. Eu acho que é essa a relação que vai demarcar. Tem uma relação que é pedagógica, mas tem uma que é o professor dizendo: "Leia isso". ( PROFESSORA-FORMADORA)

Com seus questionamentos, a professora nos apresenta a complexidade da docência e nos mostra pela sua prática docente que o ensino passa a ser negociação de sentidos dentro de uma experiência de formação que tem como emergência o heterogêneo, o plural, os questionamentos e os dilemas docentes contemporâneos.

Se a realidade é complexa, como simplificá-la pela interpretação a partir de uma só lógica, de uma só referência? Precisamos fazer um esforço de compreender como a complexidade nos mostra a necessidade de lidar com a incontornável impermanência das coisas e, por consequência, com o incontornável inacabamento das nossas compreensões, com a falta e a busca das respostas que nos atingem como docentes na complexidade.

Essas práticas (CERTEAU, 2009) marcam profundamente a epistemologia multirreferencial e o que as caracteriza são sempre nossas ações, inspirações, usos, artes de fazer, invenções. Segundo Ardoino (1998), o essencial é que toda prática é sempre um começar, uma potência da problemática alternada e articulada do tripé agente-autor-ator. 


\section{DO PROCESSO DE FORMAÇÃO AOS PROCESSOS DE CONHECIMENTO: GRUPOS DE PESQUISA ONLINE E ORIENTAÇÃO COLETIVA NO FACEBOOK}

Os grupos de pesquisa surgem como uma nova forma institucional de potencializar as condições da produção do conhecimento científico. As diversas demandas externas, oriundas das agências de fomento, e as tarefas e atividades diferentes atribuídas aos grupos de pesquisa têm gerado formas diversificadas de organização e têm motivado a construção de múltiplas experiências.

Articuladamente, em relação ao nosso assunto, o CNPq (responsável pelo Diretório de Grupos de Pesquisa ${ }^{2}$ ) define grupo de pesquisa como a ação conjunta e organizada de um grupo de pesquisadores $^{3}$ envolvidos profissional e permanentemente com as atividades de pesquisa, com linhas comuns e compartilhamento de instalações e equipamentos. Um grupo integrado de pesquisa prevê a participação de dois ou mais professores e um conjunto de alunos e pesquisadores que contribuam para a produção acadêmica. Em geral, a coordenação fica com o professor mais experiente, com maior titulação, que pode solicitar recursos junto aos órgãos de fomento $(\mathrm{CNPq}$, Capes, etc.).

Para a Capes ${ }^{4}$,grupo de Pesquisa é a denominação atribuída ao grupo de pesquisadores e estudantes que se organizam em torno de uma ou mais linhas de pesquisa de uma área do conhecimento, com o objetivo de desenvolver pesquisa científica. Além de espaços de formação de pesquisadores, os grupos de pesquisa podem ajudar a consolidar linhas de pesquisa, a aprofundar a fundamentação teórica dos trabalhos e a reduzir as fragilidades metodológicas tão frequentes nos estudos da área.

Os grupos de pesquisa da Pós-Graduação são ambiências formativas para orientandos e orientadores e possuem uma institucionalidade, ou seja: (a) registro no Diretório de Grupos do CNPq; (b) comprometimento institucionalizado de professores e alunos que participam do grupo; (c) projeto "guarda-chuva", isto é, projeto que possa conter os interesses mais amplos de pesquisa

\footnotetext{
${ }^{2}$ O Diretório dos Grupos de Pesquisa no Brasil constitui-se no inventário dos grupos de pesquisa científica e tecnológica em atividade no país. As informações nele contidas dizem respeito aos recursos humanos constituintes dos grupos (pesquisadores, estudantes e técnicos), às linhas de pesquisa em andamento, às especialidades do conhecimento, aos setores de aplicação envolvidos, à produção científica, tecnológica e artística, e às parcerias estabelecidas entre os grupos e as instituições, sobretudo com as empresas do setor produtivo. Com isso, é capaz de descrever os limites e o perfil geral da atividade científico-tecnológica no Brasil. O diretório possui uma base corrente, cujas informações podem ser atualizadas continuamente pelos atores envolvidos, e realiza censos bianuais, que são fotografias dessa base corrente. Disponível em: http://lattes.cnpq.br/web/dgp/o-que-e/ .
}

${ }^{3}$ Disponível em http://lattes.cnpq.br/web/dgp/home, acesso em 21/03/2014.

${ }^{4}$ http://lattes.cnpq.br/web/dgp .

Revista Teias v. 18, n. 50, 2017 (Jul./Set.): Conversas sobre formação de professores, práticas e currículos 
dos integrantes do grupo e que possa, dessa forma, dar ao grupo identidade temática (não se trata, portanto, do "projeto de pesquisa", conforme define o $\mathrm{CNPq}$ ); (d) relatório de atividades que contenha o projeto do grupo, a descrição sumária das atividades no período e os seus produtos.

Nesses grupos há constantemente discussões de bibliografias previamente selecionadas com o objetivo de estabelecer um campo de diálogo entre diversos pesquisadores, entre pesquisadores e alunos e requer que os participantes compartilhem instrumentos conceituais comuns. Além disso, a pesquisa está sempre em diálogo com aquilo que outros pesquisadores e/ ou linhas de pesquisa produzem.

Ao participar de alguns grupos para realizar esta pesquisa, percebemos que muitos professores, além de criarem suas disciplinas nas turmas de Graduação e da Pós-Graduação em grupos fechados e páginas no Facebook, também criavam outros com o mesmo nome dos grupos de pesquisa institucional. Nesses grupos, os quais chamamos de Grupos de Pesquisa Online, os textos teóricos e os assuntos debatidos nos encontros presenciais eram discutidos e compartilhados por seus componentes.

O que chamamos de grupos de pesquisa online são os grupos criados na interface da rede social Facebook em que se desenvolveram processos de orientação coletiva e extensões de práticas de pesquisa entre as professoras-formadoras e seus orientandos. Nesses grupos, emergiram mudanças nas formas de comunicar, além de se ampliarem as oportunidades de atuação conjunta e colaborativa entre seus membros. A inovação nos suportes que armazenam e recuperam a informação, o movimento para o acesso livre ao conhecimento, o aumento da produção científica em colaboração e a formação de redes de coautoria constituem um terreno fértil para a criação e o fortalecimento dos usos das redes sociais no campo científico.

\section{OS GRUPOS DE PESQUISA NO FACEBOOK}

Os grupos do Facebook são murais fechados, onde as pessoas que o compõem podem postar e compartilhar seu status, arquivos e links. A diferença é que essa publicação será no mural do grupo - e, por isso, visível apenas por seus integrantes - e seu formato de participação permite que tenham uma interação mais direcionada e "particular", uma vez que somente os integrantes poderão visualizar e interagir com os rastros inseridos nesse espaço. É permitida a formação de três tipos de grupo:

(1) Grupo aberto - No qual qualquer usuário da rede pode ver as informações sobre membros, tópicos e arquivos compartilhados; 
(2) Grupo fechado - Seus integrantes são visíveis, mas não membros não podem ver as publicações feitas em seu mural. Qualquer um pode pedir para participar, desde que seja aprovado por um administrador. Ainda é possível a um administrador incluir um amigo no grupo;

(3) Grupo secreto - Nesse tipo de grupo, ninguém, além dos próprios integrantes, sabe que ele existe ou quem dele faz parte. Ele é invisível para todos os demais na rede. Somente um administrador pode convidar alguém para ser um novo membro do grupo, sendo que o escolhido não pode recusar o convite. Ele é adicionado ao grupo, mas pode sair quando quiser.

Para participar dos grupos de pesquisa online enviamos pedidos de participação aos administradores, que em alguns casos eram alunos do coordenador do grupo, apresentando o objetivo da pesquisa e pedindo licença ${ }^{5}$ para acompanhar e participar das narrativas compartilhadas. No movimento de interagir com os componentes do grupo, dialogamos com os membros sobre as orientações docentes/discentes, colaboramos com as percepções dos participantes acerca da integração das atividades nos pontos significativos de apreciação de cada membro, compartilhamos textos, links, imagens e cocriamos com as análises dos trabalhos que seriam apresentados ou defendidos pelos mestrandos e doutorandos.

Após a nossa imersão, algumas questões emergiram da própria dinâmica do trabalho apresentado por cada grupo de pesquisa: Quais os tipos de apropriações e usos dos recursos do Facebook no contexto em questão? Quais as percepções do grupo sobre a articulação das atividades online? É possível fazer orientação docente pelo Facebook? Quais as necessidades dos professoresformadores ao criarem seus grupos de pesquisa em uma rede social? É possível pensarmos que as orientações coletivas podem ser realizadas através da interação em um grupo numa rede social? Que questões atravessam a pesquisa institucional e que são possíveis de serem articuladas também numa rede social?

Ao acompanhar as narrativas dos docentes, pudemos perceber o quanto elas ganham sentido e se potencializam como processo de formação e de conhecimento. As narrativas produzidas foram singulares nesse processo formativo, porque se assentavam entre as diversas experiências e aprendizagens individuais e coletivas no momento da orientação a partir da articulação dos espaços/temposda universidade com os espaços/tempos da rede social. Nossa opção foi focar não somente na relação singular, intersubjetiva e complexa da orientação, mas, sobretudo, analisar as possibilidades e potencialidades da docência na cibercultura.

\footnotetext{
${ }^{5}$ Nas pesquisas com os cotidianos, costumamos "pedir licença" como autorização ao campo e aos praticantes da pesquisa para dialogar com eles e sobre eles.
} 


\section{OS PROCESSOS DE FORMAÇÃO E DE ORIENTAÇÃO COLETIVA DO GRUPO DE PESQUISA: INFÂNCIA, JUUVENTUDE, EDUCAÇÃO E CULTURA - IJEC}

Durante a pesquisa pudemos acompanhar e vivenciar as dinâmicas que foram se constituindo na formação dos Grupos de Pesquisa Online no Facebook, e as formas como estas desenvolveram processos de orientação coletiva com o uso do digital em rede. Para isso, nos inspiramos em alguns grupos criados por professores-formadores, sujeitos da pesquisa. Neste texto, fizemos um recorte do Grupo de Pesquisa: Infância, Juventude, Educação e Cultura - IJEC, do Programa de Pós-Graduação em Educação da Universidade do Estado do Rio de Janeiro - UERJ, coordenado por uma das professoras-formadoras. Interessa ao grupo conhecer o papel mediador das tecnologias de informação e comunicação na construção - por crianças e jovens - de redes de conhecimento e significação fomentadoras de crítica, de reflexão e de ação.

\section{Cultura}

Figura 1 - Grupo no Facebook do Ijec Grupo de pesquisa Infância, Juventude, Educação e

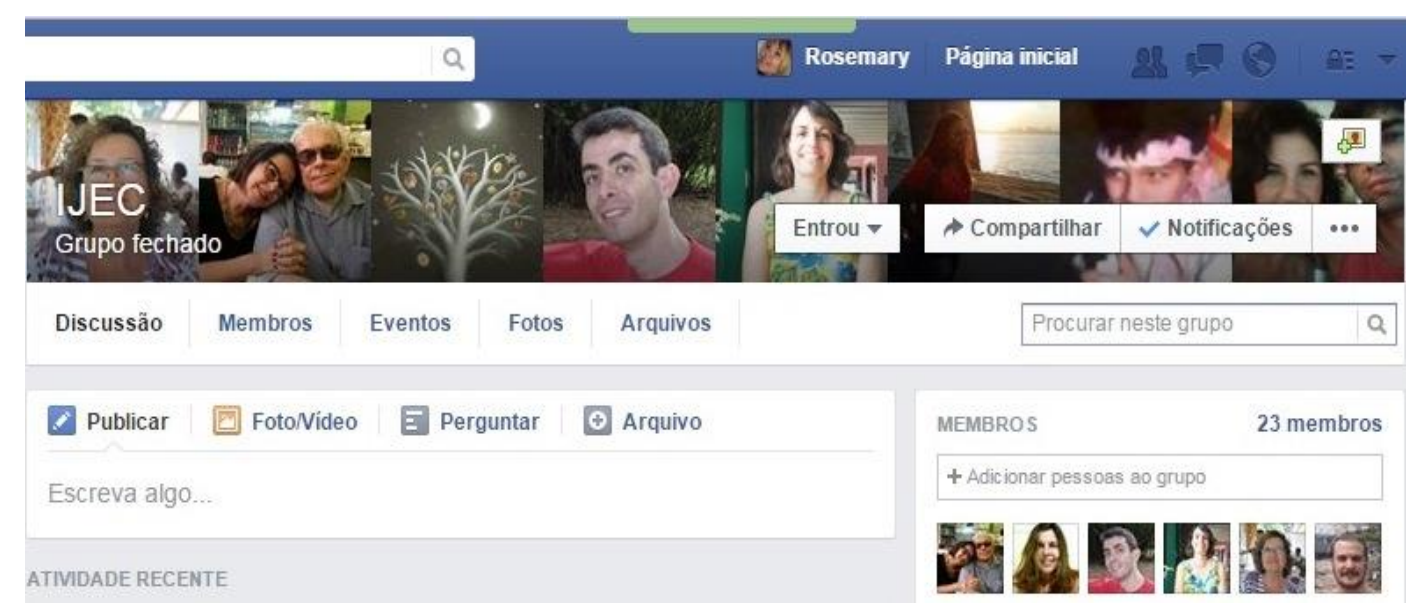

Fonte: https://www.facebook.com/groups/274681555957390/

Acompanhando as publicações do IJEC no Grupo de Pesquisa Online, vimos como a orientação da professor-formdora era implicada e atenta ao processo vivenciado na Pós-Graduação pelos seus orientandos. Esse processo é complexo, pois lança o orientando a várias situações e vivências: ele experimenta tanto a euforia, a produção caótica e rica de ideias, quanto o marasmo, a impotência total, a opacidade do objeto que ora se mostra, ora se esconde, a dificuldade de colocar as ideias no papel e a falta de vontade de trabalhar o tema escolhido. Percebemos isso na nossa 
itinerância acadêmica também dentro dos nossos próprios grupos de pesquisa. Nesse processo, o diálogo com o orientador e com os colegas que estão vivendo a mesma experiência é fundamental.

Com o objetivo de mostrar os limites e as possibilidades de fazer orientação coletiva nos grupos de pesquisa online, apresentamos algumas narrativas entre orientadores/orientandos e entre orientandos/orientandos que revelam os desafios de construção de outras ambiências formativas para a produção da pesquisa científica, particularmente na área da Educação.

Ao utilizar orientações coletivas centradas nos projetos de pesquisa dos orientandos, o orientador propicia um processo de reflexão sobre a elaboração dos projetos para todos os presentes. Para o orientando que está expondo o seu texto, funciona como mediação na compreensão dos conceitos e como um caminho a ser percorrido, para os outros, como contato com um novo conhecimento e, às vezes, como insight para o seu próprio trabalho, como podemos perceber abaixo nas narrativas de Dxxxx e seu grupo:

\section{Dxxxxx}

5 de maio

Olá, grupo querido! O texto de qualificação nasceu. Eu e Mxxxx trabalhamos muito nestes últimos dias para finalizar tudo (texto, banca, etc.). Segue o texto para vocês conferirem. Marcamos a defesa para o dia 5 de junho, quinta-feira, às $14 \mathrm{~h}$. Ainda estamos aguardando a confirmação do ProPEd para saber qual a sala. Espero que todos possam ir.

Parte superior do formulário

Axxxxx. Dxxxx meu ídolo!!!!

Professora-formadora Eu estarei lá na primeira fila

Professora-formadora Orgulhosíssima do texto corajoso do homem que conheci menino há 8 anos atrás! Parabéns, Diilton!

Guimarães Gilse Que lindo, Dxxxxx... estou ansiosa para ler... obrigada por compartilhar... eu também tenho muito orgulho de tê-lo conhecido... Parabéns... bjus

Dxxxxx Obrigado pelo carinho e lindas palavras, grupo Guimarães Gilse, saudades de você! Venha fazer uma visitinha para gente este semestre!

Dxxxxx carregou um arquivo.

29 de maio de 2014

Oi, grupo! Aproveitando que hoje não haverá reunião, quem puder olhar novamente o PPT da apresentação, eu agradeço. Fiz várias alterações, conforme vocês sugeriram. Enxuguei várias das citações e dei ênfase nos relatos dos jovens. Um bjo p tod@s e obrigado!

Professora-formadora: Dxxxxx, querido, ficou muito melhor a apresentação!!! No entanto, vc vai precisar diminuir consideravelmente os slides tanto por conta do tempo (20 minutos, no máximo 30 minutos, porque uma qualificação não vai além de 2 horas, 2 horas e meia e precisamos ouvir os 3 membros). No exame de qualificação, supõe-se que se dê ao máximo a palavra para os examinadores. Nem pensar em 97 slides!!!!!!!!!!!!!!! Aí vai minha sugestão de cortes:

Professora-formadora Estou mandando a sugestão para o email. Bjs

Dxxxxx Ok, professora, muito obrigado. Vou olhar o e-mail com calma (na verdade são 97 slides pq tem a "mini-animação"). Você tem toda razão, tentarei deixar a apresentação em torno dos 20 minutos Emoticon smile PS - agora eu fiquei me perguntando sobre a RAV124: será q o computador de lá conseguirá reproduzir a música q inicia a apresentação? Já mandei e-mail p Jorgete perguntando...

Professora-formadora Tb não sei! Mas vc não vai levar um notebook? Não se fie nos computadores da UERJ. Já mandei o email. Bjs

Dxxxxx Muito obrigado, professora! Pode deixar que não passarei dos $25 \mathrm{~min}$ vou levar o laptop da minha mae e minha caixa de som do computador, que é bem razoável. 
Vou olhar o email com calma e fazer os cortes sugeridos para não passar dos 25 min se eu nao cortar algum slide eh pq está dentro do tempo. Um bjo e bom fds

Axxxx: Dxxxx, mil desculpas pela demora, mas aí estão as minhas SUGESTÕES para a sua apresentação. Veja a pertinência delas. Como disse, são apenas SUGESTÕES!!!!! Veja aí o que cabe... Dxxxx, algumas contribuições para a sua apresentação:

1) Sb seu objetivo, slide 34:

"Desconstruir a ótica hegemônica da heterossexualidade, buscando contribuições ao campo educacional" ... fiquei pensando se a primeira parte dele não estaria mto só no plano conceitual para depois partir para a ação na educação... não sei se isso seria um problema, mas fiquei pensando... quem vai desconstruir? Vc com os sujeitos... Vcs vão dar conta dessa tarefa? Não sei se é relevante o que estou falando... talvez, seja bobeira... Bem, essa desconstrução jah é, em si, uma contribuição importantíssima...

2) Slide 35, Questão norteadora:

"Quais vínculos são tecidos entre/com um grupo de jovens no Facebook que se autodenominam homo/bissexuais?"

Quais vínculos são tecidos entre um grupo de jovens no Facebook que se autodenominam homo/bissexuais? Entre um grupo de jovens? Parece que está comparando duas coisas, mas só registrou uma. O que vc acha de colocar alguma coisa mais ou menos assim: Quais vínculos são tecidos entre os integrantes de um grupo de jovens no Facebook que se autodenominam homo/bissexuais? Ou... Quais vínculos são tecidos entre jovens de um grupo do Facebook (de jovens?) que se autodenominam homo/bissexuais? Não sei o que vc acha... na verdade, são detalhes... avalie aí....

Sb o com, é se referindo a vc com esse jovens, não é? Ta falando da sua relação com eles, certo? Então, primeiro foi entre eles e agora é com vc. Por isso, eu acho que esse "com" teria que vir separado, não poderia vir junto do "entre", pq, na verdade, são coisas diferentes... Sendo assim, meio que seriam duas questões em uma só, mas de uma forma mais separada... por exemplo, Quais vínculos são tecidos entre os integrantes de um grupo de jovens no Facebook que se autodenominam homo/bissexuais? E qual relação estabeleço com eles na pesquisa? Não sei se viajei demais...

3) Slide 38: Não sei se caberia complementar... Quais subjetividades vêm sendo produzidas pelos jovens na relação com seus pares no Facebook? Nesse msm slide, fiquei pensando em vc colocar mais uma setinha pra dar uma ideia cíclica às questões, sem início, meio e fim... ou em direção à primeira questão ou em direção ao retângulo do objetivo... pra quebrar a ideia de linearidade que se poderia supor com aquela rota.

4) $\mathrm{Sb}$ os INTERLOCUTORES TEÓRICO-ETODOLÓGICOS... ML deve ter se queixado pq Bakhtin não está no centro, mas eu acho q ficou bom por conta da ideia do círculo... Eu imaginei que vi fosse colocar cada área em um círculo diferente, fazendo com que eles se interseccionassem, mas ficou legal assim. (pena você não pegar Benjamin... tem td mto a ver... vcs estão reescrevendo a história com suas ppas narrativas... vasculhando os escombros e resgatando o passado para ressignificar o presente. O seu trabalho já é um alerta de que não dá pra deixar a história simplesmente seguir o seu rumo, para que as ruínas não cresçam ainda mais.... É preciso parar para recontá-la sob uma nova ótica, preparando o futuro para as demais gerações... e é o que vcs estão fazendo!!!

5) Slides sb os "conceitos" (que termo vc decidiu usar? Vai deixar esse msm?): $\mathrm{Sb}$ aquela parte das redes sociais... E se vc deixasse naquele retângulo apenas aquela primeira citação sb a cibercultura e falasse o resto? Bom, na verdade, eu acho que vc poderia diminuir mais um pouquinho aquelas citações, mas entendo que vc talvez fique com medo de, com o nervosismo do momento, dar branco e se perder... Se vc acha q vai ficar mais seguro assim, deixa...

E se vc deixasse ali apenas as palavras-chave? Meio que na sequencia da sua fala, pra te orientar? É uma ideia...6) Slide 58: uma bobagenzinha... vc podia dar algum destaque visual para o "Pesquisar com", que é de extrema importância. Talvez, colocando em um retângulo tb, como vc fez com "acontecimento"... é só um detalhezinho...

8) Slide 86: Detalhe sem mta importância tb... Pensei em vc dar uma sublinhada na pergunta: "Qual escola estamos ajudando a construir com os nossos alunos e na relação com nossos colegas de trabalho?" Só pra dar maior visibilidade a ela... (o que teria que se repetir, se for o caso, nos slides subsequentes...) 
, além do conteúdo do seu trabalho ser fantástico (!!!!), a diagramação da sua apresentação é linda (de tds que vc faz, não só dessa)!!!! Isso dá um trabalho enorme!!! Demonstra mta organização e bom-gosto!!

Parabéns!! Vai dar td certo!!! TMJ rs

Dxxxx: Axxxx, você é incrível! Você será uma excelente orientadora. Ou melhor, já é! Como você enumerou as suas sugestões maravilhosas, enumero também as minhas colocações para facilitar a compreensão:

1) Slide 34. Exatamente. A ideia é descontruir (ou problematizar ou desnaturalizar) a ótica hegemônica da heterossexualidade. Para isso, a parceria com os sujeitos é imprescindível. A minha aproximação com as contribuições de Bakhtin já pressupõe que o diálogo com os sujeitos me ajudará na tarefa de refletir sobre a ótica heteronormativa. Se daremos conta? Acredito que sim. A meu ver, já estamos dando conta porque as questões que eles levantam problematizam o tempo todo a naturalização da matriz heterossexual, o controle sobre seus corpos, sobre seus desejos, sobre os comportamentos esperados para cada gênero. Quando eu digo que vou desconstruir, penso que não é esgotar o assunto, mas abordá-lo sobre diversas perspectivas para mostrar o quanto as práticas sociais contemporâneas ainda trazem fortes marcas da ótica heteronormativa. Além de problematizar a matriz, os próprios sujeitos vêm apontando estratégias de resistência no combate à intolerância da escola etc. sobre aqueles que são colocados na condição de diferentes.

2) Sobre o slide 35, as questões norteadoras, vamos deixar como está, porque eu copiei e colei do texto. Estou muito curioso para ver o que a banca achará das questões. Mas eu concordo com você, Axxxx, de separar... foi difícil elaborar as questões. Mas ao mesmo tempo, penso que quando eu juntei fez sentido para mim... Sobre o ENTRE: porque é um grupo grande que se relaciona o tempo todo e nem sempre dá para eu participar

Sobre o COM: é exatamente o que você colocou. Participar COM eles das conversas.

3) Slide 38. Eu tirei jovens desta questão norteadora porque a palavra se repete praticamente em todas as outras questões. Ficaria muito repetitivo dizer JOVEM o tempo todo, num único parágrafo. Até porque ficou evidente que o foco é um grupo de jovens internautas (facebookers). Concorda?

4) Eu ia criar vários círculos nos INTERLOCUTORES. Mas quando eu fiz ficou MUITO poluído. Então achei melhor deixar todo mundo no mesmo círculo. Coloquei o Bakhtin no alto, como vocês sugeriram. Eu conversei muito com a Professora-formadora sobre incorporar ou não as contribuições de Walter Benjamin na pesquisa. Pensei que eu ficaria muito sobrecarregado, porque já estou estudando DELEUZE, GUATTARI, FOUCAULT, BAKHTIN e fora outros autores que têm me dado algumas dores de cabeça porque escrevem duro que nem pedra. Professora-formadora compreendeu o porquê de não incluir Benjamin. E eu não queria incorporá-lo de qualquer jeito, é um autor que merece uma leitura aprofundada e sem contar que é o TODO-PODEROSO da nossa querida Professora-formadora.

5) Fiz o melhor que eu pude nos conceitos (deixei assim mesmo). Coloquei um slide para cada um deles. Eu me sinto mais à vontade deixando a citação. O slide da cibercultura e redes sociais eu coloquei praticamente em tópicos porque já são conceitos que venho trabalhando há mais tempo.

6) Isso. Coloquei o PESQUISAR COM também dentro de um retângulo para dar ênfase. 7) Obrigado! Já consertei!

8) Isso mesmo! Coloquei a pergunta em itálico. Ficou legal!

Agora é tomar um Lexotan (escrevi certo?! rs) para eu não falar que nem uma metralhadora na hora. A apresentação está dando em torno de 24 minutos. Andreia, depois de suas questões maravilhosas já me sinto qualificado!! Então declaro que quinta-feira será a defesa da tese (final).

As interferências no texto de Dxxxxx nos mostram o processo da orientação coletiva entre orientandos/orientandos e a consolidação de um grupo colaborativo. Não pretendemos discutir a temática da pesquisa de Dxxxxx, pois não possuímos referenciais teóricos suficientes, mas desejamos compreender como se engendram esses processos de orientação coletiva em outros 
espaçostempos para além da universidade. Observamos que houve, por parte dos orientandos, colegas de Dxxxxx, tanto uma imersão ativa no processo construído e vivido por ele, quanto evidências das marcas que afetam o processo de criação de um texto científico e um movimento de solidariedade epistemológica como nos ensinam Alves e Garcia (2001).

Nesses encontros, a que todos e todas fazemos questão de estar presentes, aprendemos a ouvir e a falar, a criticar e a defender, a participar e a organizar, a ajudar e a ser ajudado, a compartilhar, a dar e receber, em um processo de sempre crescente solidariedade intelectual. Somos aprendizes permanentes do respeitar o outro enquanto legítimo outro, conforme Maturana e Varela. Esta aprendizagem tem contribuído para nos aceitarmos em nossas limitações, dificuldades, idiossincrasias, erros, dúvidas. A decisão de se desenvolver a orientação coletiva tem a ver com uma necessidade político-epistemológica: para desenvolver a pesquisa do/no cotidiano, precisamos do olhar do outro, o que cria um movimento irreversível de solidariedade epistemológica (ALVES; GARCIA, 2001 p.26).

Ao comentarem o princípio da orientação coletiva ou o escrever e fazer escrever, Alves e Garcia (2001) nos dizem que temos de assumir decididamente que precisamos aprender a escrever para múltiplos públicos. Segundo as autoras, cada texto é coletivo, ainda que ao final traga a assinatura individual. E mais: ao ouvirmos e debatermos as pesquisas de outros pesquisadores, somos convidados a pensar e interrogar os dados que vamos reunindo e as dúvidas que surgem em cada momento do trabalho formativo (ALVES; GARCIA, 2001).

A leitura atenta leitura do trabalho do outro, procurando contribuir nas relações com o que antes foi discutido ou lido, a organização das ideias lidas nos textos destacando formas de escrita ou conceitos importantes para a pesquisa, incentiva os demais à leitura atenta do seu texto como na narrativa da orientanda SxxxN:

22 de julho

Grupo, sei que disse que não ia mandar texto pro nosso encontro, mas estou terminando uma partezinha que fiquei devendo na qualificação, com a discussão sobre o conceito de juventudes, são "só" 7 paginazinhas...rs. Falta só o fechamento, que deixei em amarelo, pra tentar fechar melhor, tá inconcluso. De repente vcs me ajudam, críticas são necessárias, esse trecho acabou de sair do forno e tá no final do capítulo teóricometodológico. Na quinta eu apresento a estrutura da tese e vemos se ela está coerente em relação aos objetivos etc.! Beijos e até! Desde já, agradeço!

O reconhecimento da colaboração de todos é importante, como vemos na narrativa de SxxxN, pois cada um porta uma história profissional, uma experiência e um saber que pode nos ajudar no desenvolvimento da nossa pesquisa. As discussões sobre essas questões têm permitido "avançar" nas possibilidades da necessária comunicação sobre o que vamos descobrindo. Mais 
ainda: vão permitindo que, ao lermos as interferências em nosso texto, possamos perceber nossas dificuldades, limites e possibilidades para tecer melhor o tecido dos conhecimentos que vamos incorporando às nossas descobertas sobre os problemas teóricos, metodológicos, epistemológicos e políticos que enfrentamos em nossas pesquisas.

Axxxx, também orientanda pede ajuda ao grupo sobre o seu campo de pesquisa:

25 de setembro de 2014

Oi Gente, tudo bem?

Hoje foi o último dia desse ano dos cursos que estou acompanhando na SME de Niterói, só voltarão ano que vem... Por isso, acho que para um estudo exploratório, as aulas que acompanhei mais as conversas que terei com as meninas da Assessoria para saber mais a fundo sobre os cursos me dará material suficiente para o projeto. Como segunda etapa, ainda para o projeto, pensei em conversar com as professoras participantes dos cursos que acompanhei. Pensei em enviar um e-mail convite a elas com o seguinte texto: Olá tudo bem, nome da professora? Eu sou Axxx, a pesquisadora de mestrado da UERJ que acompanhou algumas aulas do curso de animação e edição de vídeos na Fundação. Como falei, a pesquisa que estou realizando busca pensar a formação de professores no contexto das novas tecnologias, Você gostaria de participar? Podemos conversar por e-mail, Facebook, posso visitar sua escola pra conhecer sua turma e batermos um papo sobre os cursos que você fez, a motivação para se inscrever, a importância dele na sua formação, os avanços que tem feito depois dele e outras coisas. Sua contribuição para a construção desse trabalho será muito bem vinda. (não sei se termino com beijos, abraços, Att, sei lá...) Caso a professora aceite, pensei em enviar um pequeno questionário para montar um roteiro a partir das respostas de acordo com cada sujeito: Nome,

Idade, faixa etárias das crianças com as quais trabalha:

Quais cursos você fez na Fundação com uso das tecnologias:

$\mathrm{O}$ que vcs acham? Bjos genteeeee

Professora-formadora Achei ótimo! Não vou comentar mais pq preciso dormir. Depois de um dia de cão estou com insônia. Se for orientar às 3 da matina adeus sono. Bjs

BxxxDx Fernandes Espíndola Adri, a partir do "podemos conversar por email...", entendi que você quer conversar com elas da forma que preferirem, por email, Facebook ou presencial. Minha única dúvida foi em relação à visita que você cita para conhecer o que elas fazem. A visita ao cotidiano escolar é um objetivo da sua pesquisa ou pode ser quanto pode não ser? Se for um objetivo você precisa deixar mais claro. Ou então não citar, de início, o interesse pela visita. Deixar para perguntar se você ode conhecer quando tiverem estabelecido um contato ou até confiança (não sei...)

Como a escrita numa rede social permanece por tempo indeterminado, cada componente do grupo pode voltar e reler os comentários dos colegas. Os participantes utilizam, compartilham e opinam sobre os conteúdos disponibilizados, ora relacionando-os ao seu tema de pesquisa, ora marcando outro colega, chamando a sua atenção com questões que podem colaborar com a sua pesquisa. Assim, todos têm a responsabilidade de ajudar os outros membros do grupo em seu processo de aprendizagem. Normalmente, é o professor-formador quem faz a mediação, contudo, cabe destacar que, pela própria dinâmica da rede social, todos os membros colaboram potencialmente com a análise dos textos e assuntos compartilhados pelos outros membros.

Para Alves e Garcia (2001), o modo que nos foi ensinado não dá conta do que hoje tentamos aprender e nos obriga a inventar novas formas de fazê-lo. Para as autoras, organizar um grupo de 
pesquisa e manter uma reunião semanal de estudo não é tarefa fácil, mas é necessária, pois o olhar do outro é componente indispensável do processo de trabalho em que estamos empenhados em compreender o compreender do outro e em processo de aprender a aprender.

A professora-formadora volta à questão da orientanda no dia seguinte:

Muito bem pensado, Bxxxx!!!! O cotidiano da escola não é seu objeto de estudo. $\mathrm{O}$ foco é a formação dos profs mediada pelas novas tecnologias. Fazer a ponte com a prática é mto legal e importante, mas pode não “caber' no prazo q vc tem pra fazer o mestrado. Pensa no que a Beta falou. $\mathrm{Bj}$

Axxxxx Então, não é mesmo o objetivo, só coloquei pra elas saberem que eu estou disposta a ir até elas, já que muitas trabalham o dia inteiro e às vezes em dois lugares, então esse encontro poderia ser no horário e local de trabalho. Essa parte ficou confusa?

Bxxxx É que eu tinha entendido que eram duas coisas diferentes. O ir ao laboratório para a entrevista presencial (se elas preferirem) e a visita à escola para conhecer a turma, como você coloca. Por isso disse que se fossem mesmo duas coisas diferentes você precisaria deixar mais claro seu interesse tanto de ir a um encontro presencial para entrevista e o encontro para conhecer a turma. Não sei se consegui me explicar

Axxxx Lá na SME eu só observei os cursos sendo realizados e as conheci, não havia tempo de intervalo, as conversas eram informais durante as aulas, as entrevistas serão nessa segunda etapa acontecesse?

Axxxxx E se eu colocasse apenas que poderia ir até a escola para que esse papo

Professora-orientadora: Adoro a orientação entre pares!!!

Nesse momento formativo de orientação online vislumbramos de maneira prática a construção conceitual da ciberpesquisa-formação como um conceito que extrapola a prescrição de conteúdos explicitados em manuais, livros-texto, portais e planos de ensino. Pensamos, agora, nas dificuldades que teríamos, como pesquisadores, de acompanhar tantos grupos de pesquisa, tantos textos e tantas discussões se não fosse pela interação na rede social. Assim, percebemos nesta orientação online a produção de texto acadêmico imbricado com as propriedades constitutivas das tecnologias digitais, entre as quais destaco: a interação social multidirecional, a expressão do pensamento por meio de múltiplas linguagens, a autoria e a coautoria, o acesso a informações disponíveis em bases de dados por meio de mecanismos automáticos de busca, o registro e o acesso aos textos e projetos de pesquisa a qualquer tempo e de qualquer lugar.

Para Santaella (2004, p.45), o ciberespaço é todo e qualquer espaço informacional multidimensional que, dependente da interação do usuário, permite a este o acesso, a manipulação, a transformação e o intercâmbio de seus fluxos codificados de informação.

Trouxe ao longo deste texto algumas questões e espero ter dado conta delas durante a sua escrita. Os professores-formadores e seus orientandos apropriaram-se dos recursos do Facebook para instituir práticas outras de orientação/formação na pesquisa acadêmica. Durante o tempo em que fiz imersão nesses grupos, inspirei-me em suas discussões também para a minha pesquisa. E isso se deu sem dúvida pela possibilidade de acessar todos os comentários de qualquer lugar e de 
qualquer dispositivo. Tenho certeza que esse foi um dos fatores que motivaram essas professorasformadoras a criar esses grupos de pesquisa online. Para (SPINK, 2014, p.14):

É esse dispositivo (de amizade, de vínculo, de rede) que nos permite a experimentação nos modos de pesquisar. Participar de pesquisas sob essa perspectiva é sempre estranhar o modo como se está sendo. É estranhar as nossas formas de conhecer. É reconhecer que método não é o meio de acessar algo, mas sim de se (re)construir no que estudamos e pesquisamos.

Concordamos com a autora, pois a experiência compartilhada provoca a expansão dos limites dos espaços e dos tempos da sala de aula da universidade, mas esta não está desvinculada e nem fora desse processo de formação e pesquisa. Pelo contrário, essas discussões penetram instantaneamente na universidade e revelam que ela está sempre vinculada aos outros espaços multirreferenciais de aprendizagem.

Esses processos não se referem ao praticante cultural em comunicação, mas à comunicação na constituição desses prticantes. Ela explica que os praticantes culturais em comunicação produzidos nos e pelos laços discursivos que os unem se encontram em uma situação de copresença e mútua afetação. No ciberespaço, a presença do outro se dá numa relação horizontal. A ação que os une em comunicação, segundo a autora, é, portanto, a ação de afetar e ser afetado pelo outro através de materiais significantes. O segundo ponto é como o cotidiano profissional professor-formador é também modificado na Pós-Graduação, pois velhas concepções profissionais vão sendo redefinidas, novas atividades são introduzidas, novos conceitos são incorporados, novas habilidades são desenvolvidas - e a produção acadêmica é uma delas.

Ao comentarem o princípio da orientação coletiva ou o escrever e fazer escrever, Alves e Garcia (2001) nos dizem que temos de assumir decididamente que precisamos aprender a escrever para múltiplos públicos. Segundo as autoras, cada texto é coletivo, ainda que ao final traga a assinatura individual. E mais: ao ouvirmos e debatermos as pesquisas de outros pesquisadores, somos convidados a pensar e interrogar os dados que vamos reunindo e as dúvidas que surgem em cada momento do trabalho formativo.

\section{CONCLUSÃO}

Encontramos nessa dinâmica de orientação a construção de uma relação de confiança entre orientador e orientandos e entre orientandos e orientandos, e a construção de uma ambiência de acolhimento, de solidariedade e de trocas entre os participantes do grupo de pesquisa online. Uma vez que um texto é compartilhado, lido, modificado numa rede social, outras conexões são 
estabelecidas e a comunicação vai se instituindo de forma hipertextual e interativa com esses materiais significantes.

O exercício de ler, acompanhar e participar das orientações coletivas nos inspirou falar de um lugar diferente daquele em que nos formamos professoras. Esse lugar impulsionou o desenvolvimento no nosso próprio processo de pesquisa. Encontro nessas narrativas um profícuo diálogo intercultural e acadêmico. Os membros dos grupos, ao discutirem as ideias dos outros, vão revelando qualidades importantes, o carinho, o respeito e a leitura atenta com o texto do outro, sem abrir mão de dizer tudo o que é necessário (Alves; Garcia, 2001). A implicação dos orientandos foi criando um sentimento de solidariedade e de corresponsabilidade com a pesquisa, pois ainda que em certos momentos haja trabalhos individuais, estes são sempre resultado do processo coletivo autorizante que o grupo criou no processo da escrita.

Ao utilizar orientações coletivas centradas nos projetos de pesquisa dos orientandos, o orientador propicia um processo de reflexão sobre a elaboração dos projetos para todos os presentes. Para o orientando que está expondo o seu texto, funciona como mediação na compreensão dos conceitos e como um caminho a ser percorrido, para os outros, como contato com um novo conhecimento e, às vezes, como insight para o seu próprio trabalho,

A pesquisa revela que a formação do formador na cibercultura forja outros espaços e outros tempos de pesquisa acadêmica e de criação de dispositivos online. Revela também que os usos do digital em rede pelos praticantes da pesquisa fizeram emergir processos de orientação coletiva, de experiências formadoras e de articulação da interface cidade-universidade, estabelecendo outros sentidos para a prática pedagógica e para a pesquisa acadêmica.

\section{Referências}

ALVES, N.; Leite, R. G. A necessidade da orientação coletiva nos estudos sobre cotidiano: duas experiências. Revista Portuguesa de Educação, 2001.

ARDOINO, J. Abordagem multirreferencial (plural) das situações educativas e

formativas. In: BARBOSA, J. G. (Coord.). Multirreferencialidade nas ciências e naeducação. São Carlos: EdUFSCar, p.58-78, 1998.

BARBoSA, J. G.; Galeffi, D.; Roberto. S. Alves. Criação e devir em formação:mais vida na educação. 1. ed. Salvador: EDUFBA, p.82, 2014.

BARROS, M. E. B. de; Zamboni, J. Gaguejar. In: Fonseca, T. M. G; Nascimento, M. L. do; Maraschin, Cleci (Orgs.). Pesquisar na Diferença: um abecedário. Porto Alegre: Sulina, 2012.

FRANÇA, V. Sujeitos da comunicação, sujeitos em comunicação. In: França, V; Guimarães, C. (Orgs.). Na mídia, na rua: narrativas do cotidiano. Belo Horizonte: Autêntica, 2006.

MACEDO, R. S. Compreender e mediar a formação: o fundante da educação. Brasília, DF: Líber Livro, 2010. 
MACEDO, R. S. A etnopesquisa crítica e multirreferencial nas ciências humanas e na educação. Salvador: EDUFBA, 2000.

MATURANA, R. Humberto; VARELA, Francisco J. A Árvore do conhecimento: as bases biológicas da compreensão humana. São Paulo: Palas Athena, 2001.

SANTOS, E. Educação online: cibercultura e pesquisa-formação na prática docente. Salvador, 2005.351 f. Tese (Doutorado em Educação). Universidade Federal da Bahia. FACED-UFBA, Bahia, p.74-76 2005.

SANTOS, R. Formação de Formadores e Educação Superior na cibercultura: itinerâncias de Grupos de Pesquisa no Facebook. 2015. 183 f. Tese de Doutorado em Educação - Faculdade de Educação, Universidade do Estado do Rio de Janeiro, Rio de Janeiro, 2015.

SPINK, Mary Jane; MEDRADO, Benedito; MÉLLO, Ricardo Pimentel. Vinte e cinco anos nos rastros, trilhas e riscos de produções acadêmicas situadas. In: Spink, M. J; Brigagão, J. I. M; Nascimento, V. L. V. do; Cordeiro, M. P. (Org.). A produção de informação na pesquisa social - compartilhando ferramentas. 1ed.Rio de Janeiro: Centro Edelstein de Pesquisas Sociais, v. 01, p. 14-3, 2014. 


\section{RESUMO}

Este texto tem o objetivo de compreender a formação do formador no contexto da cibercultura e como este vem estruturando sua atuação na docência universitária, atraves da criação de Grupos de Pesquisa online na rede social Facebook. Constituíram-se praticantes da pesquisa professores-formadores do ProPEd (Porgrama de Pós-Graduação da UERJ) e seus orientandos. A pertinência desta pesquisa inscreveu-se num amplo movimento da perspectiva epistemológica da multirreferencialidade com os cotidianos e pelo método atualizado da pesquisa-formação. A intenção primeira deste trabalho consistiu em mapear as experiências e itinerâncias do professor-formador em suas práticas cotidianas da cibercultura. Observamos que a sistematização de ambiências formativas articulando o espaço da universidade e das redes sociais criou redes de docência e aprendizagem. A pesquisa revelou que a formação do formador na cibercultura forja outros espaços de pesquisa acadêmica e de criação de dispositivos online. Revela também que os usos do digital em rede pelos praticantes da pesquisa fizeram emergir processos de orientação coletiva, de experiências formadoras e de articulação da interface cidade-universidade, estabelecendo outros sentidos para a prática pedagógica e para a pesquisa acadêmica.

Palavras-chave: cibercultura; orientação coletiva; grupos de pesquisa no Facebook

\section{ABSTRACT}

The purpose of this text is to understand the formation of the trainer in the context of cyberculture and how he has structured his work in university teaching through the creation of Online Research Groups on the social network Facebook. They were practitioners of the research teacher-trainers of ProPEd (Graduate Program of the UERJ) and its orientandos. The pertinence of this research was inscribed in a broad movement of the epistemological perspective of the multireferentiality with the daily ones and by the updated method of the research-formation. The first intention of this work was to map the experiences and itinerants of the teachertrainer in their daily practices of cyberculture. We observed that the systematization of formative environments articulating the space of university and sociais networks created networks of teaching and learning. The research revealed that the formation of the trainer in cyberculture forges other spaces for academic research and creation of online devices. It also reveals that the uses of digital networking by research practitioners have led to the emergence of collective orientation processes, forming experiences and articulation of the city-university interface, establishing other meanings for pedagogical practice and for academic research.

Keywords: cyberculture; collective guidance; facebook groups

\section{RESUMEN}

Este texto tiene el objetivo de comprender la formación del formador en el contexto de la cibercultura y cómo éste viene estructurando su actuación en la docencia universitaria, a través de la creación de Grupos de Investigación online en la red social Facebook. Se constituyeron practicantes de la investigación profesoresformadores del ProPEd (Porgrama de Post-Graduación de la UERJ) y sus orientandos. La pertinencia de esta investigación se inscribió en un amplio movimiento de la perspectiva epistemológica de la multirreferencialidad con los cotidianos y por el método actualizado de la investigación-formación. La intención primera de este trabajo consistió en mapear las experiencias e itinerancias del profesor-formador en sus prácticas cotidianas de la cibercultura. Observamos que la sistematización de ambientes formativos articulando el espacio de la universidad y de las redes sociales creó redes de docencia y aprendizaje. La investigación reveló que la formación del formador en la cibercultura forja otros espacios de investigación académica y de creación de dispositivos en línea. También revela que los usos del digital en red por los practicantes de la investigación hicieron emerger procesos de orientación colectiva, de experiencias formadoras y de articulación de la interfaz ciudad-universidad, estableciendo otros sentidos para la práctica pedagógica y para la investigación académica.

Palabras clave: Cibercultura; Orientación colectiva; Grupos de búsqueda en Facebook 